\title{
One-to-one Digital Classes and Writing. A Case-study Perspective
}

\author{
Francesca Scenini \\ Università Milano Bicocca, Dipartimento di Scienze Umane per la Formazione Riccardo \\ Massa, Laboratorio Informatico di Sperimentazione Pedagogica, Italia
}

\begin{abstract}
Digital texts and digital practices of writing are dramatically different from analogical ones. According to this scenario, the new millennium literates are supposed to have complex and crossmedia skills of searching, evaluating, using, creating and sharing texts. In this paper, a selection of results of a multiple case study carried out within Plan Ceibal, Uruguay, an OLPC project, in 2009-2010 are presented. The research focused on exploring if, and how, children's literacy skills and practices change when the personal learning environment consistently includes the ICT and the Net A mixed method, combining quantitative and qualitative approaches, and developed in order to analyze the process by which the children of the case study give shape and meaning to written texts with analogical or digital media. The results show important differences in the approach to texts and suggest guidelines to schools and teachers involved in the change of traditional didactics to digital learning.
\end{abstract}

\section{Introduction}

Literacy is a pre-requisite for democracy and for an active and value-based citizenship and, obviously, reading and writing are key competencies for personal and social development. Literacy experiences and practices are influenced by and develop out of a context that includes culture, history, social influences [1] and technology. Indeed, communication technologies - among others change the perceptive organization of how subjects relate to their environment. Today, constant use is driving to the fore a particular perceptive code of space-time we must face while building identity. [2] And so, digitalized and electronically transmitted communication have an impact capable of modifying the human cognitive biological system, the construction of the self and the organization of the social system. Thanks to the widespread diffusion of digital media and networks, the distinction between the analogical world and the digital world - between real life and virtual life - has slowly waned. The new media have changed how space and time are perceived, changing their scope and de-materializing them. The outcome is known as de-spatialised simultaneity. [3] The digital media's unique features impact teaching and learning. Indeed, by using digital media one can create immersive environments that involve multi-sensorial stimuli; one can also create complete and repeatable educational experiences. Multimedia representations make it possible to manipulate and explore concepts and abstractions; extended memorization facilitates the creation of a personalized learning plan. Being able to create future scenarios is a valuable resource for learners who actively build their own knowledge. The portability of many digital devices extends the field of learning indefinitely. Furthermore, the network created with digital technology strengthens and speeds up the inflow and outflow of information, making subjects the centre of new functional and cognitive balances. In early 2010, World Bank Senior Education Specialist R. Hawkins brilliantly summed up [4] ten worldwide tendencies concerning the influence of technologies on modern-day education. These processes relate to the changes - at a micro-level and in global cultural-democratic development - in the technological resources available for optimizing learning (mobile learning, cloud computing, smart portfolio assessment), the influence of technologies on learning space and time (ubiquitous learning, redefinition of learning spaces), the use of technologies to create, systematize and communicate educational contents (gaming, personalized learning, teacher-generated open content, teacher manager mentors), whereas, I believe, the tenth tendency (one-to-one computing), which is also the subject of my studies, includes most of these macro-phenomena.

Actually, the context is fluid and ever-changing and a consequent transformation of reading and writing is arguable. For centuries, the activity to select, codify, memorize and transmit information, has been externalized by writing individually, in alphabetical code, on organic supports. Today, the practices of reading and writing are changing from analog to digital support and tools, from linear text to hyper-text, and from individual to collaborative activity. The Internet provides new text formats, new styles of reading and writing and new ways to interact with information and share it. Being literate, nowadays, means to be able to read and write shifting from analogical to digital code, media and 
contents. In fact, on the one hand, children's personal learning environment is ever more digital and fully connected. But, on the other hand, the cultural heritage is mostly analogical and the majority of digital contents the learners use is thought, created and transmitted by people who grew up in a mainly un-digital and web-less society.

For this reason, the ability to correctly understand and manage the alphabetical code remains a necessary competence for an autonomous and meaningful use of the ICTs. However, the educational system must renew literacy as goal, to provide a model of how to effectively empower in children the development of a complex cross-media literacy competence which includes functional, critical and active literacy. A new kind of literacy should be proposed by formal learning to empower a positive approach to the interaction between analogical and digital codes, media and contents that means a positive way of co-constructing on-line and off-line identity, relationships, conversations and culture.

Firstly, is necessary to understand what is happening to children's literacy development when the personal learning environment, as a context, is fully digitalized and highly connected. Even if, actually, it is impossible to know if kids who grow and develop their literacy skills in a digital environment are spontaneously transliterates, focusing on the case study of the $1: 1$ computing classes I collected evidences that children, when in contact with digital media, naturally adopt transliteracy as a way of expression and empower their transliteracy skills.

\section{New literacies}

Many research projects were focused on defining literacy competences in the 21th century. On the one hand, digital literacy seems to include basic technical skills: "knowing" and "knowing what to do" [5]; on the other hand, it includes "knowing how to be" and "knowing how to act/react" [6] and hence knowing how to choose, understand, process, re-transmit information conveyed via digital media in a social and / or collaborative context.

Others were focused on how writing with a computer affects literacy, writing processes and texts [7] [8], highlighting in particular new linguistic usages and hypertextual practices. Indeed, with the digital coding of information and computers, it is possible to easily create a non-linear text structure, turning a text into a hypertext or hypermedia (if different codes are used together: alphabet, icons, sound) featuring an access that is potentially open and a variable hierarchy of information.

Actually, we know what happens when we read a text on a screen [9], how eye movement and attention focus, and some researchers argue that digital reading competence can be defined as transliteracy: the ability to read, write and interact across a range of platforms, tools and media from signing and orality through handwriting, print, TV, radio and film, to digital social networks. [10].

However, there is still a lack of evidence about what happens to children's literacy development when the personal learning environment is fully digitalized and highly connected. It is arguable that when every learner has, and can share, ubiquitously, hardware, software, and connectivity it means every learner can contribute to construct and can share symbolic systems, meanings and practices. It is plausible that when "digital saturation" will be reached in the children's personal learning environment, a change in practices of teaching and learning will be necessary.

The whole research was motivated by the following broad questions:

1. Is there a visible effect on writing practices by the introduction of the one-to-one model?

2. What about the effect of sharing writing experiences?

3. How do children get information from the Internet to solve a given issue?

4. Are there visible benefits by the introduction of a digital socio-constructivist approach in the first years of primary school?

In this paper I discuss the first point to make preliminary remarks concerning the complete investigation.

\section{Field and population}

This study took place in the context of the One Laptop Per Child Uruguayan project "Plan Ceibal", with the collaboration of Uruguayan Administración Nacional de Educación Pública. The study was conducted in two phases: from May 2009 to December 2009 and from July 2010 to August 2011

The pilot project of the Plan Ceibal began in the department of Florida in 2007; in 2009 it expanded to Montevideo and its metropolitan area (about half of Uruguay's population). All children of public elementary schools there received an MIT XO laptop and started a learning activity based on digital and collaborative online work, taking advantage of the potentiality of research, elaboration and communication of digital media information and peer learning [11]. Students not only received the devices and instructions for their use, but the Plan provided for all the educational settings to be remodeled according to the potentialities of the digital cooperative media and the constructionist pedagogical approach.

This study is in fact a multiple case study. I worked both with children who started primary 
school in the 1:1 model, and children who did not. The choice is to focus on two groups of children with comparable partner socio-economic extraction. This is because the economic and family conditions of the involved children are considered as factors of notable influence on the dynamics of learning; these factors are particularly meaningful considering the condition of Uruguay as a "developing country" where there are still situations of structural poverty and lack of goods of first necessity and an economic and cultural unbalance among the different social classes.

The first group of 20 children was chosen from a third grade of an elementary school of a village where the Plan Ceibal started as a pilot project in 2007. It is a typical rural installation of the department of Florida, north of Montevideo. The school has 197 pupils and has classes of 24.5 students on average with a $7.6 \%$ of school year repeaters. These children received their first formal learning experiences in reading and writing with digital media; they know and use the tools of digital interaction and communication; they are used to experience collaborative activities, in class, with the use of digital media.

The second group of children is a group of 40 , belonging to two classes of an elementary school in the Cerro, department of Montevideo. Cerro is a district in the outskirts of Montevideo inhabited by middle- and low class families (workers, artisans etc.); it features a vast zone of slum or precarious installations without primary infrastructures and conditions of structural poverty. The school has 364 pupils, with classes composed of 25.2 students on average and a $9.9 \%$ of school year repeaters. These children have received their first formal learning of reading and writing in analogical; they are used to face-face interaction, and to individual production. With the implementation of Plan Ceibal, they receive hardware (XO), i.e. a laptop, designed specifically for children so as to ensure functionality and proper ergonomics, low energy consumption, always connected and suitable for multimedia work, with pre-loaded free and open-source SUGAR software. SUGAR is a Linux interface designed specifically for primary-school teaching. Finally, net infrastructures are supplied to the school and its vicinity.

\section{Methodology}

The methodology for this case study was chosen so as not to quantify the topic's complexity in terms of isolated data, but rather to provide an actual method that would make it possible to inferentially and systemically investigate what happens in the educational context, in order to be able to interpret the outcome as thoroughly and comprehensively as possible in relation to the issues to be analyzed.
Furthermore, the case study's methodology seems inherently suitable for education studies. Hence, the case study was chosen so as to favour thoroughness over breadth and to make it possible for the results to be explained with words [12]. Since the aim of the case study is not to list frequencies (statistical generalization) but to develop and generalize theories (analytical generalization), this design includes data collected with diverse tools, depending heavily on the research aims and questions. A mixed methodology merging a qualitative and a quantitative model, based on the analysis of children's education and socio-economic background and literacy practices, was adopted. Firstly, I collected data to provide information regarding the children's socioeconomic conditions and their media consumption habits at home through interviews (to children, teachers, directors) and questionnaires (to teachers, parents). Then, the analysis focused on the analysis of the didactic practices through unstructured observation (shadowing) of the classes with the aid of ethnographic notes and analysis of the previous didactic activities. The children were observed in a first phase during the class activities, spontaneously conducted by the teacher and the children. Subsequently, 4 tests of individual textual production and collaborative writing with traditional (pencil-paper based) and digital media (XO laptop based) were administered and repeated three times, during the following nine school months. The text analysis was both syntactic and semantic. I focused on the quantity of written words per text; the quantity of written sentences per text and the number of words per sentence; the quantity of non-standard words per text and the type and quantity of punctuation marks used per text. What is more, I analyzed each text with respect to coherence, cohesion, complexity and care for layout.

\section{Results}

Particularly interesting results came from a preliminary, non-participating observation of the classes during their spontaneous activities. I was able to observe not just the classroom's physical setting (environment and infrastructures) but also the children's and teachers' behavioral habits. I was also able to glimpse the level of computer literacy, the reading and writing abilities, the attitude and the degree of effectiveness of individual and group work.

During this phase, it became clear to me how the teachers are aware only of the basic functionalities of the $\mathrm{XO}$ and see laptop activity as complicated because of their lack of knowledge of how applications and networks work, and their lack of basics such as file-saving and web-browsing. Still, 
the teachers say they are in favour of introducing computers into teaching and, in general, see computers as useful tools in curbing behavioral issues.

The teachers' approach in the reading and writing activities seemed consciously focused on enhancing and improving the children's expressiveness and imagination, rather than on their formal correctness and on the communicative functionality of their papers. For instance, group dynamics during collaborative and cooperative tasks were carefully monitored by the teachers, as was the children's behavior, so as to ensure harmony and peacefulness; less importance was given to the quality and quantity of interaction among the children, to role assignment and responsibility within the group, to everyone's actual contribution to the task at hand.

Let us now examine the family context. We must take into consideration the parents' schooling and the media the children are exposed to at home. On average, the parents of the children taking part in the case study completed their primary education only. Of the two parents, the father is generally the more educated. In three classrooms (81 children from 79 families, there being two pairs of brothers), $57 \%$ of the families own encyclopedias; 20\% own novels and fiction; 75\% own children's books (these, however, may be the books provided by the school, as the school provides one textbook per year). Reading and writing exercise is perceived more as a school activity; indeed, the teachers claim they hardly ever assign any homework because the children spend most of the day at school. Furthermore, around one family out of three (35\%) owns a computer in addition to the XO: $43 \%$ of the families of analogical children, with $12 \%$ also having an Internet connection and $26.3 \%$ of those of digital children, none of whom have an internet connection at home other than that provided by Plan Ceibal. In more than half the cases (57\%), the children live with someone who uses a computer on a weekly basis, usually the mother or siblings; this suggests the typical Uruguayan family structure, where the father is busy with out-of-house activities which, in the rural and industrial areas of the country analyzed in the case study, rarely require the use of technology.

Another interesting fact emerged concerning $\mathrm{XO}$ use: at home, $77 \%$ of children use it daily, whereas $9 \%$ never use it. $4 \%$ of the latter specified that this is because their XO is broken; another $4 \%$ claim they have no WiFi signal at home and prefer using their home computer. The interviews to the children show a marked preference for web-based games and activities, especially music- and video-downloading. An irrelevant number of children claim they use the $\mathrm{XO}$ to browse the web and only when required to do so by their teachers (this figure is biased by the high number of districts with no WiFi coverage).

Another significant figure concerning the children who have had the XO for three years is that only $8 \%$ of the parents claim they play a role in teaching their children how to use the XO; $51 \%$ believe the teachers taught them, $25 \%$ that they learned from their peers and, most interestingly, $16 \%$ that their children are self-taught. It is especially significant that very few interviewed children claimed they taught any of their family members how to use a computer, and this concerns mostly brothers, sisters or cousins. Indeed, most children say their parents cannot use or do not want to use the $\mathrm{XO}$. The parents of the children who received the computer during the third year of primary school, however, unanimously claim they are favourable to the plan's implementation; they believe it will provide the children and the teachers with learning resources and ensure their children greater job opportunities.

The parents of the children who received the computer during the first year of primary school are equally in favour: on average, the children's sociability does not seem to diminish, nor does the time dedicated to other artefacts such as TV or books; however, their opinions are contradictory concerning easier learning due to computer use.

Lastly, the unstructured observation of children supported by the analysis of interviews (data gathered from 22 children, 3 teachers and 2 school managers) and questionnaires (to teachers and parents) suggested that the introduction of laptops in school activities increases writing motivation through increased control, epistemic curiosity, task involvement and persistence. The data seem to confirm the independent development of digital and handwriting sensorimotor processes. I collected evidence about the differences in children's handwriting and computer writing.

I observed a statistically significant difference between the number of words in handwritten and computer-written texts. Computer-based writing appears to be slower. We know that the process of writing includes sensorimotor, perceptual and cognitive activities [9]. In digital writing, graphemic representation, when we pass from the cognitive representation of real referents to the sensorimotor action, is interpolated by the visual identification on the keyboard and the process to search for or remember the position of the right key.

Furthermore, when writing with a computer, the planning phase and sensorimotor action are necessarily dissociated from the monitoring act which is made by raising one's head and looking at the video. It is interesting to notice that, even if both the children who started their formal learning of writing with the XO laptop and the children who had the laptop introduced in the third grade, wrote more words in the pencil-paper based tests, the number of 
words they could write per text grew, on average (with a comparable variance) in accordance with the frequency of laptop use in classroom and their paperand-pencil writing experience did not seem to provide any significant advantage (see Figures 1 and 2 ). While the children wrote more words when they were asked to write with pencil and paper, they wrote more complex texts when using the laptop. The texts produced with the laptop feature more sentences, more cohesion (pronouns, ellipses, lexical substitutions) and more connective elements (above all: connectives of time, place, cause and effect).

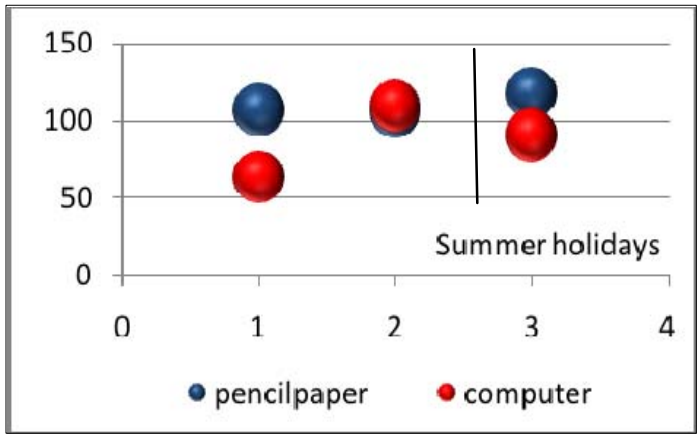

Figure $1 . \mathrm{N}^{\circ}$ of words per text on average - Children who have been using the laptop to write since the first grade

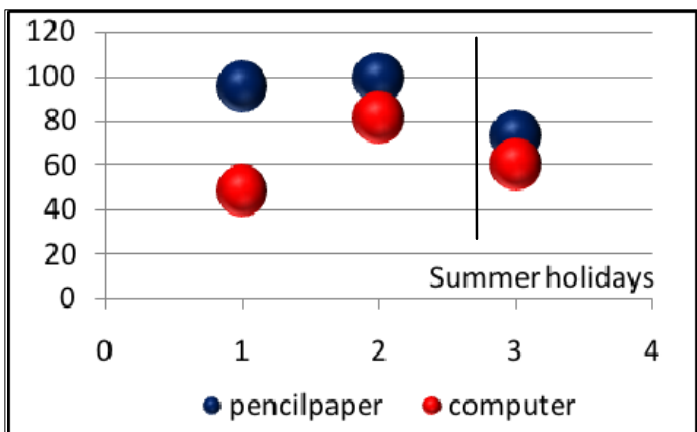

Figure $2 . \mathrm{N}^{\circ}$ of words per text on average - Children who have been using the laptop to write since the third grade

In handwriting, punctuation helps authors to structure and hierarchically organize their texts on the predefined space on paper. It is interesting to notice that, writing with laptops, children (especially children who have used the laptop to write since the first grade, see Figure 3) used, on average, a consistently lower number of punctuation marks per sentence.

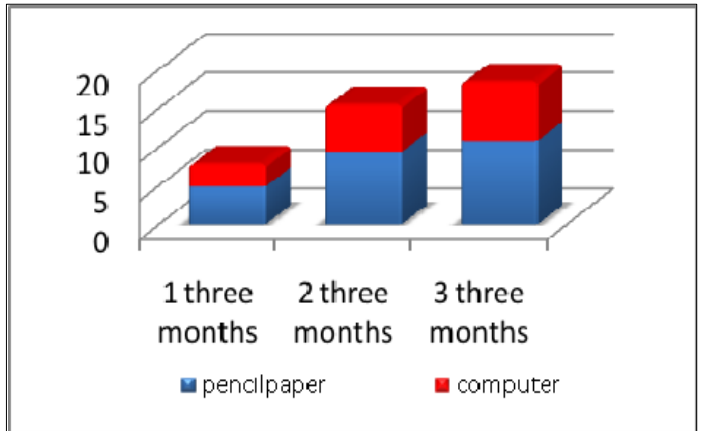

Figure 3. $\mathrm{N}^{\circ}$ of punctuation marks per text on average Children who have been using the laptop to write since the first grade

Instead, there is no statistical relationship between the use of a word processor with a spell-checker and the number of non-standard words in their text. This suggests that the children (and probably the teachers) did not know how it works.

In addition, the results show a statistically significant difference in the number of graphic elements on average per text between handwritten and digital texts. Writing with the laptop seems to empower children's use of colors and graphical elements to enrich their works (see Figures 5 and 6). Our data are aligned with the hypothesis of a remediation of the traditional text into a new type of text in which iconic, alphabetic and audio-visual elements converged.

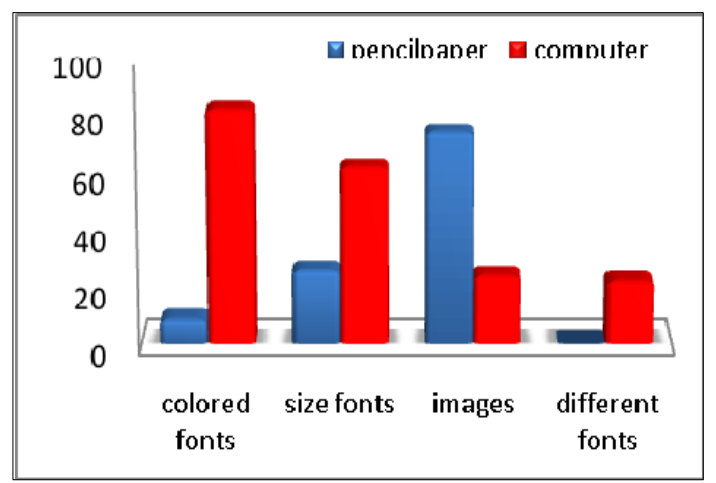

Figure $4 . \mathrm{N}^{\circ}$ of graphical elements per text on average - Children who have been using the laptop to write since the first grade 


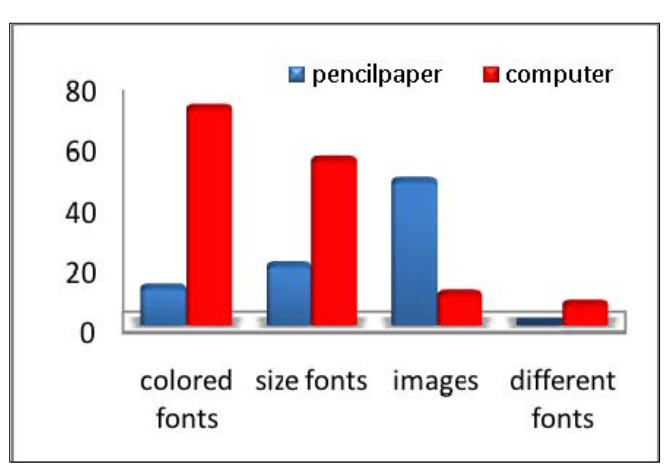

Figure 5. $\mathrm{N}^{\circ}$ of Graphical elements per text on average Children who have been using the laptop to write since the third grade

Interestingly, when we consider the aforementioned quantitative criteria, the computer tests show no statistically significant differences between the groups if the results are crossed with the gender. No statistically significant differences emerge even if we cross the data with the education level of the mother (chosen as the household figure of reference) or with the levels of computer literacy and frequency of usage of one or more family members. This may confirm the hypothesis that the children's families provide little support to and participation in the children's school activities, and that there is a lack of home study, as confirmed by the interviewed teachers and children. If we take the presence of books at home (children's books, encyclopedias or novels) as a variable to establish the significance of the difference between the average of the analyzed figures, this seems to have more impact on the calculations referred to the analogical children. Although preliminary, these data suggest that the computer is - for the digital children with no books at home - a source of information that has somehow decreased the difference due to the lack of printed information available at home.

While incomplete, these data can provide indications concerning the independence (or lack thereof) of learning processes and the practices of digital and analogical writing.

\section{Conclusions and future objectives}

The proposed analysis of the technology, of the paradigms and of the case-study's results shows clearly how digital technology in a one-to-one environment has positive peculiarities insofar as access and the development of textual information processing and communication skills are concerned; these effects are triggered by the motivational involvement originating from the use of digital media and from being connected. Interestingly, the implemented tests hint at how owning an internetconnected laptop for children taking part in a one-to- one education plan starting from their first school year seems to have effects that somehow contrast the lack of printed material at home. As for the children's writing skills, I believe that the use of the computer as a writing tool as well as the immersion into the forms and possibilities of digital textuality also play a significant role. Taken as a whole, these aspects may give the children of the one-to-one classes significant procedural advantages and extend their scope of expression when access to facilities and digital skills occur together; this is precisely the goal of Plan Ceibal, the context of my study. Nevertheless, the case-study outcomes suggest that this result may not be achieved shortly; this is due in particular to infrastructural problems on the one hand and to the lack of support of teachers and families on the other. The positive effect of laptop use on children's writing strictly depends on the frequency of use and on teacher tutoring. For instance, the analysis of the results shows how the motility of typing requires constant exercise for the results to be comparable to paper-and-pencil writing, regardless of when the technology is introduced. Computertyped texts by children are usually shorter, but the gap with hand-written texts decreases if we look at the results from a longitudinal perspective. Computer-written texts, while shorter, seem more articulate and consistent that hand-written texts. The use of punctuation marks is not more significant; this suggests that the perception of increased topographical quality on-screen and spell-checking encourage sloppier punctuation in favour of a better spatial, and not symbolic, organisation of the text. Care of graphical elements, favoured in general by the possibilities given by word-processing, fails when, as in text-image integration, there is a technical difficulty the children cannot effectively overcome. Observing the children and their texts shows that spelling and grammar checks are difficult to carry out; their usage is not intuitive for the children and is not taken advantage of by the teachers.

These simple observations suggest that the spontaneous nature of the native digital as a junction in the web-based society on the one hand, and the wide-spread nature of web-based knowledge on the other, should be carefully reconsidered as not necessarily technologically decisive. This research shows that ICTs have had a positive impact on children's writing performance, but these benefits are lacking where the learners do not find, in their learning ecology, enough support to enable them to devise problem-solving strategies and obtain results with as much as or less effort than when using traditional technology.

The data confirm the basic assumption of my research approach that it is not the quantity of technology available at school that makes the 
difference, but the degree to which it relates to the fields of experience already explored by the children and the extent to which it is used to encourage active and creative learning on their part. The future goal is to plan how to include in the formal teachinglearning experience the use of applications and basic tools for searching, understanding, collecting and communicating information.

\section{References}

[1] S.C. Switzer, Multiple mode of communication of young Brazilian Children, in : Narey Making meaning: constructing multimodal perspective of language, literacy and learning through Arts-based early childhood education Springer, 2008, pp. 133-34.

[2] D. Buckingham, The media literacy of children and young people: A review of the research literature OFCOM, London, 2005.

[3] J. B. Thompson, The media and the modernity, a social theory of the media, Stanford University Press, Stanford, 1995.

[4] G. Pecchinenda, Videogiochi e cultura della simulazione, Laterza Editore, Bari, 2003.

[5] R. Hawkins, 10 Global Trends in ICT and Education, https://blogs.worldbank.org/edutech/10-global-trends-inict-and-education> 18 July 2012.

[6] E. Morin, I sette saperi necessari all'educazione del futuro, Raffaello Cortina editore, Milano, 2000.

[7] G. Le Boterf, Costruire le competenze individuali e collettive, Feltrinelli, Milano, 2009.

[8] N. Baron, Alphabet to email: How written English evolved and where it's heading, Routledge, New York 2000.

[9] L. Toschi, Il linguaggio dei nuovi media, Apogeo, Milano, 2001.

[10] J. Nielsen, Designing Web Usability: The Practice of Simplicity, New Riders Publishing, Indianapolis, 2000.

[11] DSPE, Dirección Sectorial de Planificación Educativa, Propuesta de evaluación de impacto del proyecto CEIBALUruguay, Conectividad Educativa Básica Aprendizaje Línea, DSPE-ANEP, 2007.

[12] Yin R. K, Lo studio di caso nella ricerca scientifica, progetto e metodi, Armando Editore, Roma, 2005. 